\title{
Stock Recovery
}

National Cancer Institute

\section{Source}

National Cancer Institute. Stock Recovery. NCI Thesaurus. Code C54700.

Removal or correction by the manufacturer company of a product that has not been marketed or that has not left the direct control of the firm, i.e., the product is located on premises owned by, or under the control of, the firm and no portion of the lot has been released for sale or use. 